\title{
THE IMPORTANCE OF BEING OPEN: HOW EUROPEAN OPEN UNIVERSITIES CAN REPOSITION IN THE POST-PANDEMIC HIGHER EDUCATION LANDSCAPE
}

Antonio Moreira Teixeira, Universidade de Lisboa, José Mota, LEaD - Universidade Aberta, Portugal

\section{Abstract}

Open universities (OUs) have been at the forefront of educational technology. Designed as innovative and flexible organizations, they have proven instrumental to assure the consolidation of research, innovation and quality practice in distance and online education. Inspired by the impact of open education and MOOCs, traditional higher education institutions began embracing technology-enhanced learning and online education. The growing competition from these universities, as well as of new non-formal providers, have resulted for the OUs in the decrease in student numbers, especially in Europe and North America. With the closing down of campuses due to Covid19, this growing movement was noticeably accelerated. As higher education prepares for the new normal, how may the European OU remain socially relevant and competitive? Are they still indispensable for assuring quality education opportunities for all, as a growing number of critics question? In this paper we analyse the impact of the pandemic on European OU, discuss possible strategies to meet the challenges of a rapidly transforming higher education landscape, and identify potential trends and models for future development.

Keywords: Distance Education, Open Universities, Online Learning, Open Education, Higher Education, Covid-19.

\section{Introduction}

For a long period, since the early 1970's, European open universities (OUs) have been at the forefront of educational technology. At the turn of the millennium, with the accelerated development of digital and connected technologies, they have led the transition to online education, setting the standards for quality practices based on their accumulated knowledge and extensive experience of delivering education at a distance (Weller, 2020; Schuwer \& Mulder, 2009; Sangra, 2002). A critical factor supporting this spearheading role 
was the OUs' continuous and consolidated leadership in research and innovation in the field of open and online education. (Weller et al., 2018) Moreover, that ground-breaking attitude was strongly anchored in a generation of inspired and often visionary leaders, who knew the field and were, in most cases, also researchers and practitioners.

That scenario is long gone now. In the last decade, OUs have evolved to more mainstream and traditional processes and structures. Leadership has become more professional, even if more detached from the field. In general, OUs have tended to blur in the growing crowd of open education providers and lose that strong differentiating identity from the past. As a consequence, many OUs in Europe have experienced a significant decrease in student numbers and most lost political leverage and power over the years (Teixeira et al., 2019).

The impact of Covid-19 seems to have caught the world by surprise, and that includes Higher Education as well. The long tail effect of the pandemic on universities, which will endure for some years, will push them all to compete directly with OUs in the increasingly hybrid education territory (Witze, 2020). In this emerging context, what kind of response could OUs provide to keep competitive? Are they still indispensable to the higher education systems for carrying out the mission of assuring quality education opportunities for all, as a growing number of critics have come to question?

\section{Methodology}

The research process was based on a literature review using both white and grey literature. Careful consideration was given as to the quality of the information sources. The process had 3 stages: first, we reviewed the models of organization and operation of the historical European OUs (OU UK, UNED, Fern Uni, OU NL, UAb and UOC) and collected evidence on how they have responded throughout time to technological and pedagogical change and variable social contexts. Subsequently, we collected evidence on the impact of the pandemic on higher education institutions (HEI) and, in particular, on the OUs' mitigation strategies. Finally, we built a predictable scenario of evolution for the OUs' organization and operation based on the critical analysis of the previous findings.

\section{How distance and online education saved higher education worldwide in 2020}

Distance and online learning saved higher education in 2020. Faced with the impact of the pandemic, which forced universities to shut down their campuses worldwide, the only way for them to be able to carry on with their mission was to migrate all teaching and learning activities online. In such an unprecedented context, most universities proved to be unprepared, making use of emergency remote solutions (Hodges et al., 2020). 
Unskilled and untrained for their role in this new educational context, most teachers tried to replicate their traditional classroom experiences by simply delivering lectures online through web conferencing systems. In spite of a massive joint effort by authorities, educational institutions, professional organizations and communities, it became evident that most teachers didn't have the necessary digital literacy, or the competences and skills needed to deliver high quality online-based teaching (Gewerc et al., 2020). Across all education subsectors worldwide, similar problems could be identified: difficulties in addressing digital divide issues; teacher and student excessive work overload and consequent digital fatigue; unawareness of personal data privacy and management issues; and a general misconception regarding digital assessment methods (Watermeyer et al., 2020; Sahu, 2020; Reimers \& Schleicher, 2020).

If the pandemic crisis has mostly scaled up and sped up an ongoing process of digital transformation of higher education, the unforeseen scale and speed it reached in the last months has introduced a new set of problems and challenges which must be addressed by both policy and research (Hodges et al., 2020; Gewerc et al., 2020). One major conclusion which can be drawn from the crisis is the inefficiency of most of the extensive training and capacity building in online learning carried out in the last decade in traditional universities.

Although OUs proved to be much better prepared for this emergency scenario, still they had to struggle with some difficult, unforeseen challenges. The virtual classrooms remained open and activities kept running as usual. However, similarly to all other universities, the entire faculty, support staff and student body were now teaching, working and learning from home; many in poor conditions, most needing extra care and attention. Good and fluid communication became paramount as well as an increased attention to mental health and well-being of faculty and students. Although teachers used appropriately designed pedagogically approaches, students experienced digital fatigue and forms of depression due to the social context and family environment. Moreover, OUs had to move their student assessment system entirely online almost overnight which proved challenging.

\section{In the aftermath of the pandemic: All universities go online}

Having the time and the resources to move beyond a crisis mitigation stage, traditional universities are seizing the opportunity to speed up the process of digital transformation. The aim is to be able to operate in the new digital or hybrid environment keeping the highest academic standards. Despite some resistance from older faculty members and public criticism from opinion-makers, traditional universities worldwide are steadily preparing for the challenges of the new normal. But what does it mean specifically? 
To successfully complete the transition to distance and online education, universities will need not only to adjust their methodologies and procedures, but also to transform their organizational culture (Teixeira et al., 2019). The first step for this sustainable transformation will be to assure that governance and university leadership are focused on promoting educational innovation. This implies that they develop a holistic vision which can inspire the university community, align strategic planning with it, and engage all actors in the process.

Also very important for universities will be to develop a digital educational ecosystem which includes not just the learning environment - with the learning management system, the digital repositories, the virtual and remote labs and the e-assessment system - but also the administrative and all other support services. Being this a cultural transformation process, universities should also open up this ecosystem, promoting the use, reuse and remix of open educational resources, and assuring universal accessibility and digital inclusion (Czerniewicz, 2018).

This period of emergency remote teaching has made only more obvious the recurrent difficulties conventional HEI have always had to adopt good practices in distance and online education. By ignoring decades of experience in the field, they are condemned either to resort to familiar, traditional methodologies that do not translate productively to the online context, or to improvise half-baked solutions that focus on technology and gimmicks without the needed pedagogical insight and instructional design strategies.

The digital transformation of traditional universities depends fundamentally on how successfully they develop online pedagogy. For this, establishing a reference model for teaching and learning practices similarly to what the OUs have done will be paramount. Such a framework is quite helpful for both teachers and students, allowing them to adjust their respective practices in this new environment. Another critical point, which became quite evident during the current crisis, is the need to assure quality learner support, especially in such a challenging social context as the one we are all experiencing. The digital transition should lead to a more participatory learning culture, now that changes in how knowledge and information are produced, transmitted or distributed in networks often escape the control of organizations and institutions and, consequently, to solutions that match these new realities in the form of participatory pedagogies. Learning and assessment should be based on trust and collaboration; thus the growing importance of the ethical aspects involved. As Weller (2020; p.189) points out, "the role of technology is becoming ever more pervasive in the educational process". 
However, universities' readiness to overcome the challenges of the new normal will depend mostly on how well they are able to prepare their faculty. Going back to the basics, it's urgent to rethink teacher professional development both in traditional universities and the OUs. The crisis has highlighted the importance of teachers' digital competences, but in order to be effective, teacher training has to be conducted in authentic contexts. This implies teachers should be trained in immersive online-based settings and not in traditional in-person environments. Otherwise, they won't be properly prepared as they won't have the experience of learning online.

\section{How to navigate in the new post-COVID 19 higher education landscape?}

Since the early 2000's, digital education has been expanding across HEI worldwide (Teixeira et al., 2019). However, as Taylor signalled (2001), universities started a fifth generation of distance education from a nonsystemic development of scattered initiatives, often the result of random acts of innovation performed by risktaking individual academics. His e-University at the University of Southern Queensland proved how this projects should be "strategically planned, systematically integrated and institutionally comprehensive” (Taylor, 2001).

The move to the online environment has been seen as a natural step in the evolution of all the HEI (van der Zwaan, 2017). In the process, most universities also acquired experience in open education, especially in the form of MOOCs. In spite of some unfulfilled promises, MOOCs have raised the profile of ed tech in general, and open practice in particular (Weller, 2020). Moreover, "MOOCs generated a significant amount of media attention and hype" (Weller, 2020; p.130), as probably no other educational technology before. Yet, this scenario didn't lead to a dominance of the distance education universities' model within higher education systems. While the Anadolu University in Turkey, with its student population of over 2 million (Anadolu University, 2019), and the OUs in Asia and Africa continue to attract hundreds of thousands of students each, opposite to what happen in Europe.

The UK's OU faced severe challenges in recent years because of cuts to funding from the government. The same happened with other OUs, which have also seen a decrease in enrolments. A similar phenomenon has occurred in Canada with the more specialized distance teaching institutions, such as the Athabasca University and the Téluq University (Allen \& Seaman, 2014; Bates, 2017). In fact, the provision of distance and online education by OUs seemed clearly challenged by the unprecedented and rapid popularity of MOOCs in the last decade. This follows on the threat represented initially by the emergence of open educational resources (OERs) and other freely available content on the Internet (Teixeira et al., 2019). The same can be stated about blended or hybrid learning, where students can 
combine campus-based and online learning. With much more flexible opportunities for studying, there could be less demand for full distance learning.

Thus, a growing range of competitors have been emerging in the traditional distance education market. All these developments mean that for on-campus universities, what was previously a specialized activity somewhat on the periphery of an organisation (and, hence, organized and often funded differently), had now moved into the core. There is, therefore, a tendency for distance education to be swallowed up in a myriad of diversified practices, most of them without any proper support, both theoretical and practical, to guide their conception and implementation. These phenomena were greatly amplified by the impact of the pandemic in higher education.

In this new adverse context, critical mass and organizational flexibility seem to be critical for the OUs to respond. A perfect example of this was the "Conectad@s: la universidad en casa" (UNED, 2020) initiative in Spain. Faced with the need to design a portal with learning resources to support the emergency online transition of Spanish universities, the Ministry of Education and the Rector's Council speedily jointly launched a project whose development was led in collaboration by the National Distance Teaching University (UNED) and the Open University of Catalonia (UOC), with the contribution of all other universities. This successful initiative proves the capacity of the OUs to rise to the occasion and quickly address any emergency or a critical social need (Tait, 2013). But do all European OUs have the required dimension, resources and innovation capability to meet these complex challenges?

Their potential for social intervention can be also expressed in smaller scale. Two significant examples of this can be found in the UK and Portugal in the context of Covid-19. Through Future Learn, UK's OU has decided to offer a free online course on "COVID-19: Tackling the Novel Coronavirus" (Future Learn, 2020). Designed by the experts at the London School of Hygiene \& Tropical Medicine it aimed at fighting the conflicting information on the internet and social media. The response was astounding, as over 25,000 learners have signed up, from almost 200 countries. In Portugal, the community of distance and online learning researchers and experts, mostly from the Portuguese OU (UAb), have set an open online community to support the transition to online education, "Ensinar a Distância" (2020), which attracted a large interest and the active collaboration of some of the world's leading experts in the field. 


\section{Can open universities reinvent themselves?}

Digital technologies are increasingly becoming embedded and distributed in many of the objects and spaces we inhabit and with which we interact. Digital twins, Internet of Things (IoT), block chains, and Artificial Intelligence (AI) promise to redefine our imagination and future vision of education. All HEI need to deal with this fastchanging landscape and provide adequate forms of access, integration and inclusion. However, as Moore (2007) points out, simply adding technologies to courses does not automatically assure their quality. Using the new technologies to pursue old teaching methods - generally, the content-centred, knowledge transmission approach that has been the paradigm in traditional universities - does not bring substantial gains.

It should be expected that the OUs will be in a better position to deal with the current challenges than traditional universities. Given they have built throughout their history a unique body of research on teaching methodologies and accumulated a large experience of pedagogical innovation, successfully adapting to different technological generations. In fact, traditional universities tend to introduce new technologies and practices as simply a mimetic replacement of conventional teacher-centred approaches. This is clearly demonstrated in the way academics in conventional HEI have misinterpreted the MOOC concept. Ignoring all the previous research and experience in the field of distance education and online learning, the methodologies adopted did not stray too far from the familiar lecture (Teixeira et al., 2019). The same is happening now, with the dominance of videoconferencing platforms as almost the only strategy used, with endless hours of synchronous sessions being confused with modern and effective distance and online learning.

Even if more prepared to deal with a changing technological and social environment, OUs themselves have however struggled to adapt to the pedagogical challenges and opportunities offered by the Internet and social media. Innovative universities, as described by Christensen and Eyring (2011), should evolve from a closed to an open network environment, one in which data and resources are openly and freely shared with fellow institutions and also the community. Such a major change in academia and its validation practices, as well as in many other aspects of how HEI operate), can be hard even for the OUs. Higher education has historically avoided competitive disruption and even the most flexible universities are traditionally very stable organizations, keeping its basic structure and processes unchanged over the years. This is why leaders find it so difficult to reengineer universities as learning organizations.

Christensen and Eyring (2011) explain this obstacle as a result from the power of prestige in the higher education marketplace. In the absence of comparable measures of what 
universities produce for their students, the well-respected institutions have a natural advantage. In the case of OUs, a related stabilizing force which has impeded disruptive innovation results from regulation and also from the accreditation process, which in the past made conformance to tradition the price of entry to the industry (Teixeira et al., 2019).

The only way for the OUs to remain an attractive alternative to those seeking a rewarding and modern education is to be able to differentiate themselves once again as institutions specialized in distance and online learning, with a keen pedagogical and instructional innovative approach that incorporates the consolidated and the emergent methodologies and practices: a learning process contextualized by a strong social dimension; an emphasis on a culture of collaboration and of shared construction of knowledge; the promotion of an effective dialogue and interaction with people, resources, and artefacts; the facilitation of a diversified process of encounters, experiences and reflections; a commitment to openness and transparency; a blending of formal, non-formal and informal learning based on networks that interact with one another.

When the OUs were created in the seventies and eighties, they stood apart because they were organised according to an innovative model, which unbundled the typical components of the teaching process in order to be able to reproduce at scale, reassembling them in a new format. By unbundling once again teaching and learning processes and outsourcing services (Teixeira et al., 2019), as well as re-bundling them into new forms (Czerniewicz, 2018) according to variable contexts, OUs will gain increased flexibility, critical dimension and resource capability. This will allow them to respond to a rapidly changing environment, thus carrying on their mission of providing quality learning opportunities for all. But, by doing it in such a way, they must go against an important part of their DNA and tradition, which is to continuously grow bigger in size (Christensen \& Eyring, 2011). The new approach should be to cooperate within networks. The transition to such a disruptive innovation-based model requires vision, time, detailed planning and consistent development.

\section{The key is open research \& innovation, and social agency}

As Tait describes, OUs "through scale and flexibility [...] can in terms of social policy provide a pressure valve to release frustration about educational opportunity; can deliver large scale opportunities for professional development that support improvement in quality of service and economic growth; and can support the development of an educated citizenry and so nourish self-fulfilment and democracy." (Tait, 2013; pp.5-6). The core mission of the OUs, independently of regional context, is to educate for individual transformation and social change. OUs shouldn't lose that ultimate goal of their activity, as it's what gives them substance and relevance. 
The uniqueness of OUs' legacy lies also in another major factor. The introduction of educational technology has not been aimed at increasing teaching and learning efficiency, but at making the process accessible and affordable for all, as well as flexible to every context. Educational research and innovation are thus at the core of every OU identity and should be taken as such by institutional governance. But in order to be coherently practiced, it should be organised within a similar open framework to the one described in the previous section. The concept of open science has extended the same principles of openness of the educational process to the whole research cycle as well. OUs should therefore spearhead the reorganization of research and innovation practices, applying the principles of their own educational philosophy and promoting open access, open publication, open data, open peer review, open innovation, and open licensing. This is not yet the scenario, however, since not many European OUs seem to be at the forefront of the open science movement.

\section{Conclusions}

Faced with a growing competition in distance and online learning from traditional HEI, and at risk of losing the leadership in research and innovation on educational technology, the European OUs are recognizing the need and the urgency to reorganise and adjust to a new emerging higher education landscape. How should they position in this new context? How can these institutions remain relevant and competitive?

The findings from our research show that the OUs have still a major role to play. This is being demonstrated in the current pandemic crisis. The OU's mission, values and tradition equip them well to address the social inequities which arise from the global digital transformation. In order to pursue that goal, the OUs need to adopt a more caring and personalised pedagogical approach and rebuild their institutional identity around the notions of openness, innovation and social agency. In addition, their operation model should be updated as to enable them to fully embrace these core values. But, from a disruptive and more differentiating perspective. Findings suggest also that the OUs would benefit from adopting fully open network-based collaborative environments, unbundling their processes and outsourcing services, sharing resources and developing a true knowledge digital ecosystem.

\section{References}

Allen, I., \& Seaman, J. (2014). Grade Change: Tracking Online Learning in the United States. Wellesley, MA: Babson College/Sloan Foundation.

Anadolu University. (2019). Anadolu at a Glance. Retrieved from

https://anadolu.edu.tr/en/about-anadolu/institutional/anadolu-at-a-glance 
Bates. A. W. (2013, October 23). Is there a future for distance education? E-learning and distance education resources: Tony's Blog [blog post]. Retrieved from https://www.tonybates.ca/2013/10/23/is-there-a-future-for-distance-education.

Bates, T. (A. W.) (Ed.) (2017). Tracking Online Education in Canadian Universities and Colleges. Nova Scotia: Canadian Digital Learning Research Association.

Christensen, C. M., \& Eyring, H. J. (2011). The Innovative University. Changing the DNA of Higher education from inside out. San Francisco: Jossey-Bass.

Czerniewicz, L. (2018). Unbundling and rebundling higher education in an age of inequality. EDUCAUSE Review, 53(6), 10-24. Retrieved from https://er.educause.edu/articles/2018/10/unbundling-and-rebundlinghighereducation-in-an-age-of-inequality

Ensinar a Distância. (2020). Comunidade Aberta e Inclusiva de Apoio à Transição Para a Educação Online. Retrieved from https://eagoraead.wixsite.com/ensinaradistancia

Future Learn. (2020). COVID-19: Tackling the Novel Coronavirus. Retrieved from https://www.futurelearn.com/courses/covid19-novel-coronavirus

Gewerc, A., Persico, D., \& Rodés-Paragarimo, V. (2020). The Emperor has no clothes: the COVID-19 emergency and the need for digital competence. IEEE-RITA, 8(4).

Hodges, C., Moore, S., Lockee, B., Trust, T., \& Bond, A. (2020, March 27). The difference between emergency remote teaching and online learning. Educause Review [Blog post]. Retrieved October 3, 2020, from https://er.educause.edu/articles/2020/3/thedifference-between-emergency-remoteteaching-and-online-learning

Moore, M. (2007). Web 2.0: Does it really matter? American Journal of Distance Education, 21(4), 177-183. Retrieved from http://www.informaworld.com/10.1080/08923640701595183

Reimers, F., \& Schleicher, A. (2020). Schooling disrupted, schooling rethought. How the Covid-19 pandemic is changing education. OECD. https://globaled.gse.harvard.edu/files/geii/files/education_continuity_v3.pdf

Sahu, P. (2020). Closure of Universities Due to Coronavirus Disease 2019 (COVID-19): Impact on Education and Mental Health of Students and Academic Staff. Cureus, 12(4), e7541. https://doi.org/10.7759/cureus.7541

Sangra, A. (2002). A new learning model for the information and knowledge society: The case of the Universitat Oberta de Catalunya (UOC) Spain. The International Review of Research in Open and Distaance Learning, 2(2) 
Schuwer, R., \& Mulder, F. (2009). OpenER, a Dutch initiative in Open Educational Resources. Open Learning: The Journal of Open, Distance and e-Learning, 24(1), 67-76. doi: $10.1080 / 02680510802627852$

Tait, A. (2013). Distance and e-learning, social justice and development: the relevance of capability approaches to the mission of open universities. The International Review of Research in Open and Distributed Learning, 14, 4. Retrieved October 3, 2020, from www.irrodl.org/index.php/irrodl/article/view/1526/2632

Taylor, J. C. (2001). Fifth Generation Distance Education. Higher Education Series. Camberra: Department of Education, Training and Youth Affairs - Higher Education Division. Retrieved from http://www.c3l.unioldenburg.de/cde/media/readings/taylor01.pdf

Teixeira, A., Bates, T., \& Mota, J. (2019). What future(s) for distance education universities? Towards an open network-based approach. RIED - Revista Iberoamericana de Educación a Distancia, 22(1), 107-126. http://dx.doi.org/10.5944/ried.22.1.22288

UNED (2020). Conectad@s: la universidad en casa. Retrieved from https://www.uned.es/universidad/inicio/uned_uoc_solidaria.html

Watermeyer, R., Crick, T., Knight, C., \& Goodall, J. (2020). COVID-19 and digital disruption in UK universities: Afflictions and affordances of emergency online migration. Higher Education (2020). https://doi.org/10.1007/s10734-020-00561-y

Weller, M. (2020). 25 Years of Ed Tech. Edmonton: AU Press.

Weller, M., Jordan, K., DeVries, I., \& Rolfe, V. (2018). Mapping the open education landscape: Citation network analysis of historical open and distance education research. Open Praxis, 10(2), 109-126.

Witze, A. (2020). Universities will never be the same after the coronavirus crisis. How virtual classrooms and dire finances could alter academia: part 1 in a series on science after the pandemic. Nature, 582, 162-164. doi: 10.1038/d41586-020-01518-y

van der Zwaan, B. (2017). Higher Education in 2040: A Global Approach. Amsterdam University Press. doi:10.2307/j.ctvfp63n9 